\title{
Knowledge, Computer-mediated Communication, and Sustainable Development
}

\author{
Andreas Metzner-Szigeth
}

\section{The Nexus between Cultural Diversity, Sustainable Development and the European Knowledge Society}

Society does not become "sustainable" by itself - even in the transition from an industrial society (intensive in resources) to an information society (intensive in knowledge). ${ }^{1}$ For this reason, it is necessary particularly for the advanced nations (if they want to follow a lasting path that is harmless to the environment and capable of handling the demands of the future ) to merge the guiding model [in German: "Leitbild"] of the "information", "communication" or "knowledge society" with that of "sustainable development" in way that is useful (cf. Spangenberg et al. 2002).

The European Union has - at least! - made a declaration in this regard. At its Lisbon summit in March, 2000, it was stated that: "the Union has today set itself a new strategic goal for the next decade: to become the most competitive and dynamic knowledge-based economy in the world, capable of sustainable economic growth with more and better jobs and greater social cohesion" (European Council 2000). Perhaps the term "worlds apart" doesn't quite apply here, but we all know that - there are often huge gulfs between an expression of intent, a self-obligation, and its implementation.

In order to make some headway on this ambitious path, it is first necessary to (carefully) figure out the divergences and convergences between these models and the aims and objectives they recommend, between possible futures and practicable paths. Beyond the public relations work, the EU Commission is of course also aware of this, and - in Priority 7 "Citizens and governance in a knowledge based society" of its $6^{\text {th }}$ framework programme - it announced support of a research intention that targeted precisely this issue. ${ }^{2}$

1 The implications of this "transition thesis", regarding the shifting relationships between the production and wealth factors of labour, capital, nature and knowledge (cf. Hilty/ Ruddy 2002; Hodgson 2000; Stehr 2001), are of enormous importance, of importance not only for environmental sustainability, but also for the state of affairs in the employment market and for the occupational crisis, that is for the economic and social dimensions of sustainability.

2 There it is stated: "The EU is fully committed to the pursuit of sustainable development as well as to the establishment of a European knowledge society. Research may address 
Without wishing to anticipate a detailed analysis - it is clear that the workability of bridge constructions like the "durable information and knowledge society" or a "sustainable networked knowledge-based economy and society" first needs to be proven (cf. Johnston 2002; Jokinen et al. 1998).

"Information and communication technologies" (ICTs) are frequently regarded as the particular "key technology" for transition into the much debated "knowledge-based economy and society". Scientific, cultural and genuine social sources of knowledge and understanding are neglected although they are of no less importance. This has tradition in so far as socio-economic goals are often intended to be attained by technological innovations in the first place. So also in the "Information - Society - Technology" program of the European Commis$\operatorname{sion}^{3}$, technological innovations are expected (are ascribed the capability) to be able to de-link economical growth from environmental degradation, to create a multitude of new jobs, or to help close the gulf between rich and poor in the European as well as on a global scale. In this sense ICTs are the core element of the hope for a technology-driven transformation of the European economies towards advanced, that is more effective, clean and fair, production and consumption patterns (cf. Baker 2000). Independently of whether one likes to share this optimism or can do so - these desirable destinations do not realize themselves automatically. Moreover, this hope for a break-through based on technology seems to omit an adequate "addressing" of important elements of the European society model. There is above all the trinity of freedom, equality and justice, as well as, the principles of their shaping, e. g., the division of power or constitutional obligations, and the primacy of politics, which are - as purposes - not just to be achieved simply by the commitment of technological means, but are by contrast to be respected from a technological "means" and their progress.

the compatibilities as well as possible tensions between these two key strategic objectives. This will require comparative analysis of their discourses, policy strategies and governance practice" (EC 2002). In an other part of the same document (under the title: „Research Area 2: Options and choices for the development of a knowledge-based society") it is additionally stated: "The objective is to develop an integrated understanding of how a knowledge-based society can promote the societal objectives of the EU set at the Lisbon summit and subsequent European Councils of sustainable development, social and territorial cohesion and improved quality of life, with due consideration to the variety of social models in Europe and taking into account aspects relating to the ageing of the population" (EC 2002).

3 Cf. for this pre-decision Bangemann 1994 and EC 1994, where the European Commission agrees to the conclusions of the Bangemann-report with regard to the role of market mechanisms as driving forces. Cf. furthermore, with changed tenor, EC 1997, ECFIS 2000 and EC-IST. Cf. also Keil-Slawik 1996 to the "reasoning triangle" of the lead of the Japanese, Americans and Europeans and its effects on the political initiatives for the promotion of information technology. 
Finally we can assume that the "new" information and communication capacities and their association with the processes of globalisation are equally containing shaping options as challenges (cf. Lubbers/Koorevaar 2000). Both point to the fact that the transition to more "sustainable" consumption and production patterns will depend on adequate preparation for the decision processes - that are pressing on all levels of society. This demands the participation of well informed citizens and for advice by experts, who are scientifically at the "latest state of knowledge", not only with regard to the "technologies", but particularly with regard to their possible "results" and their recognizable sustainability and shaping "potentials". The "transition" to the "information" or "knowledge society", depends on the society's foregoing "extent of being well-informed", and on the spreading of "knowledge" about options and consequences (cf. Schomberg 2002). The different options and consequences of the use of the very same technology can result in increasing the consumption of environmental resources or in reducing it, in eroding the social cohesion of society, or in stabilizing it, or in breaking down or building up the societal ability for economic growth. Consequently "innovation" should be determined in a broader sense. It has to be designed as a multiple and integrated socio-technical process, which takes the institutional, economic, social and environmental aspects into account right from the outset. Although it may be managed successfully to bring such a "system" into position, the battle may still not be won. However, it may be achievable to shape the promising possibilities of the ICTs in such a way, that they are capable, at least, to carry and to support a transformation process. That is going in the "right" direction of a "sustainable" knowledge society.

The connection between sustainability and knowledge - and with it a key issue within the decision power play - has so far been seen predominantly from one-sided, functional or instrumental premises: knowledge is in this case at the disposal of durability. Added to this is the "environmental bias", or the "ecological one-sidedness" of the sustainability debate. With the help of knowledge, natural resources should be protected, expenditure reduced and pollution diminished.

Essentially, another approach is to be favoured: our dealings with knowledge. This applies to the complete cycle of knowledge formation, knowledge transportation and exploitation of knowledge. The forms of its social organisation and regulation are no less important for the success of sustained development than the way in which we deal with ecological resources.

With "culture", the procedure is analogous. In the relationship between sustainability and culture it is often understood in a way that its role is fixed, as if culture functions at the disposal of sustainability. It should, for example, force back material lifestyles and spending habits and replace them with supposedly more culturally valuable ones. Having any kind of relationship between nature 
and culture at all is what distinguishes humankind. The form, content and shape of this relationship characterises each particular society. Thus if there is something that is fundamentally relevant to sustainability, it may lie hidden in this relationship. Culture is therefore, a priori, a dimension of sustainable development. My suggestion is that it has to be also explicitly recognized as such.

Sustainable development does not function one-dimensionally. All dimensions of sustainable development - ecological, economic, social and politicalinstitutional - are interdependent. ${ }^{4}$ This also applies to the "cultural dimension", which certainly doesn't only include art and cultural assets in the sense of "high culture". And it would even still be viewed in too narrow a sense if popular and everyday culture were added.

Culture is the medium of the self-realization of the human being as a human being. It follows from this that the concern is with culture in the basal sense of an inter-subjectively divided area of consciousness of the pattern of meaning of individual behaviour and social life, and with this a knowledge and communication landscape that aims to be formed in a sustainable manner. ${ }^{5}$

In this context I would like to present the following hypothesis: sustainable development, in terms of its dependency on knowledge and communication, brings with it many requirements, i.e., it is considerably more demanding than any non-sustainable path of progression.

The reasons for this are: 6

- $\quad$ Systematically optimising societal use, i.e., including social and ecological "costs" in calculations and decision-making processes, instead of selectively maximising it, requires greater scientific and technical knowledge. Also required are considerably more contextual knowledge, and more intensive and extensive information, communication and negotiation processes between a growing number of actors taking part or affected.

- $\quad$ Finding solutions for social problems, that do justice to all of the diverse rules of sustainable development (for instance how it represents the integrative approach of the "Hermann von Helmholtz Community of German Research Centres"7), is a highly co-ordinated process, which must con-

4 As a cross cutting issue to these "dimensions", the "factors" of "time" and "space" are of cardinal importance. Both should be elaborated systematically in any conceptualization of sustainable development. This is true especially regarding the growing significance of the changing relationships between "real" and "virtual" realities and their consequences for building up new regimes of coordination between actions, perceptions and communications (cf. Bühl 2000, pp. 156ff.; Castells 1996, pp. 376ff.).

5 Cf. the notion of culture that is developed in Banse/Metzner-Szigeth 2003.

6 Cf. Metzner 2002, especially chapter 5, where these arguments are elaborated in detail.

7 Cf. Kopfmüller, et al., 2001, where this integrative approach is formulated. 
sider all dimensions of sustainability in terms of their individual characteristics and peculiarities. In each case one's own knowledge is to be considered, communicated and put to the most diverse tests to the same extent as that of other social actors.

- The depth of intervention and consequence effectiveness of industrial activities in the structure and processes of nature grown out of industrialtechnological development is only the other side of the coin. The change in form of ecological consequences finds its equivalent in social consequences. For these, too, the temporal and spatial expansion, shift and change in emphasis as a consequence of decisions is characteristic, as well as the confused, uncertain scattering of probabilities and risks. To comply with this development, to assess it and to even be able to properly regulate it, demands a corresponding intensification and acceleration of the acquisition of knowledge and its communicative distribution and imparting.

Science and research, education and upbringing, art and culture, media and information, society and consumption - the cycle of the emergence of knowledge, the transportation of knowledge and its evaluation cannot be categorised into any individual social arena, sector or subsystem: it runs through them all!

The supremacy of social structure, organisation and regulation of this cycle therefore cannot be left to any individual social system, either (only) the market or (only) the state.

\section{Exploration of the Complex of Knowledge, Computer-mediated Communication and Sustainability}

There is no doubt that at present the whole cycle of knowledge of society is being changed and presented with (fundamentally) new challenges by the solidness and speed of the development and engagement of ICTs in general and "computer-mediated communication" (CMC) in particular, and in terms of the requirements for its course and development. The enlightened view is therefore clear: the "technological" aspect of this occurrence is only the surface above a tide of economic and political decisions.

Under the title, "Organising the dealing with knowledge and information according to the principles and goals of sustainability - the ecology of knowledge in electronic areas" (cf. FA-CI 2002; translated), the Committee of Experts Communication and Information (FA-CI) of the German UNESCO Commission has worked out an "outline" with a series of suggestions addressing a range of problems. 
Elaborated as ten "building blocks of a knowledge ecology under sustainable principles" (cf. Kuhlen 2003; translated) ${ }^{8}$ they comprise:

(1) Free access to knowledge and information.

(2) Banning of discrimination - overcoming the digital divide.

(3) Securing the commons.

(4) Securing cultural diversity.

(5) Retaining creativity and innovation.

(6) Securing medial diversity.

(7) "Right to communicate".

(8) Control of technological information assistance through development of information competence.

(9) Long-term archiving and securing of knowledge.

(10) Securing of freedom for private development.

Starting from the objective to organize a broad discourse in the public such that "a consensus, compatible with the principles and destinations of sustainable development, can be achieved about our dealing with knowledge and information" (FA-CI 2002, p. 5; translated) these elements reflect a dispute. This dispute has to be carried out under the guiding-aspect to scrutinise the current tendency to reinforce the private, legally amplified and by technical means perfected disposition over and utilization of knowledge as opposite to its free public disposal (FA-CI 2002, p. 5). In spite of this origin-sided characteristic the ten recommendations represent themselves in their references quite heterogeneously, as will become clear in the subsequent explanation.

Ad (1): The element of "free access to knowledge and information" is associated basically with two points:

- Knowledge should not be shortened, following interests of its short-time "commodofication" or commercialisation.

- The free, public access to knowledge has to be guaranteed under fair conditions.

Both are necessary, so as to maintain the precondition for being able to recognize the knowledge of the past and the present in order to utilize and to generate benefits out of it.

Ad (2): With regard to the "banning of discrimination" and "overcoming the digital divide" the following is stated:

8 In so far as the "building blocks" are equivalent in their sense to the "outline" just mentioned and have come from the same author, they will be used here in order to explain the outlined suggestions in more detail. 
- In order to enable all people to employ the media of knowledge acquisition, fissures in the access and use of knowledge must be eliminated. In this case disparities in the gender-perspective, in the field of education and in the procurement of information and communication competences are to be considered.

- Also in a global sense, this is not only a question of knowledge resources, but also of possibilities to upload ones own knowledge in order to be able to represent one's own culture worldwide and to share and to develop it with others inside of the electronic spaces.

Ad (3:) The building block "securing the commons" is broken down as follows:

- Knowledge should not be put under complete private disposal, because it is - as a common good of humankind - the reservoir out of which new knowledge is created.

- $\quad$ Furthermore, this combination of knowledge as a resource and knowledge as a product is the basis for many other sustainability relevant purposes: for the evolution of science and technique, for the individual creative evolution, for the protection of cultural variety, for the enlightened participation in the democratic process and for the innovative prosperity of the economy.

$A d$ (4): The issue of "securing cultural diversity" is explained like this:

- As a "common heritage of humankind" "cultural diversity" is as important for its further evolution, as the preservation of "biodiversity" for evolution in the realm of nature.

- Cultural diversity is also the precondition for the development of individuals in the present as well as for the cultural development of future generations.

Ad (5): Under the title "Retaining creativity and innovation" a purpose is outlined basically:

The destination is to find a reasonable, fair and lastingly effective balance between private, commercial and public, free use (and/or utilization) in order to support economic development and - above all - in order to ensure the ability for economic development permanently.

Ad (6): The issue "securing medial diversity" is established as follows:

- Regarding their threat through processes of denationalisation and concentration, the conservation of medial multiplicity (also with respect to "contents") is a precondition for political-institutional sustainability, in so far as it serves to guarantee that there is enough space for the formation-proc- 
esses of the public will and the articulation of convictions, in order to maintain the development ability of democratic societies.

Ad (7): The "right to communicate" occurs as a basic human right and contains the following:

- Concerning the relationship (of enabling and tension) between mass media and modern ("media-") democracies, it would not be wise to conserve the monopolistic power of the mass media instead of using the capacities for bi- and multi-directional communication, that are offered by CMC, Internet and new media.

- If (relative to existing restrictions) new potentials for more participation emerge, making use of them becomes a right, in so far as they open up options not only to participate in governmental or administrative decisionmaking-procedures, in processes of public "agenda-setting", and in processes to organize a reasonable and critical public discourse that prepares decisions adequately.

Ad (8): The meaning of "control of technological information assistance through development of information competence" is introduced as follows:

- To be able to decide by oneself about the use of information resources and the knowledge contained in them constitutes information competence and is part of the destinations of knowledge economies following sustainable perspectives.

- To these informational resources appertain "artificial intelligence" applications such as "information assistants" or "software agents", expert systems or search machines that are vital for the use of the "world wide web" (WWW).

- The delegation of duties from "actors" to "agents" is not supposed to provide that people lose their informational autonomy or their right of selfdetermination.

Ad (9): The target of "long-term archiving and securing of knowledge" is justified like this:

- Faced with the "diffusive" character of electronic information, suitable technical and organizational measures are to be taken in order to maintain the effectiveness of cultural memory under changed conditions and to safeguard the long-term availability of electronically represented knowledge, by ensuring the convertibility and interoperability of different systems (of hardware and software).

Ad (10:) The necessity of measurements for the "securing of freedom for private development" is supported particularly with the following argument: 
- That society in which any action, whether under private, professional or public circumstances, can easily be made subject of electronic surveillance (from governmental or business agencies or simply from "hackers" or competitors) requires effective regulation and protection of the "privacy" of its citizens.

Granted - the "ten elements" presented here are essentially a "demand catalogue," that would be good to establish without an explicit appeal to sustainability, i.e., in the sense of environmental problems. In front of the scenery of a sustainability understanding of this kind, the connection of the ten elements with the sustainability-problem in general would remain as "slack" as the term "knowledge ecology" would remain "external" to the matter. The situation looks very different, however, in front of an understanding, which focuses on the "non-sustainability" of the developmental patterns of our civilization. Accordingly, such formative notions as stated here of a "knowledge ecology", refer to the necessity to overcome the limitations of sector views of societal problems, by opening up "scientific disciplinary" pre-understandings. Regarding the vanishing point of "holistic sustainability science" (cf. Kates et al. 2001), there is the threat that it may become overly complex. It may occupy itself with everything without being able to redeem its promise to consistently describe the interdependencies among its diverse subjects and to analyse them integral in their dynamics (cf. Metzner 1998). The approach described here seems to be a legitimate and thoroughly promising way.

Unfortunately, there is no space to comment on these ten elements in more detail. The "spirit" running through the suggestions, however, can be summed up in the following passage. The

"development of knowledge and technology, individual creative development, securing of cultural diversity, enlightened participation in public democratic events, and not least also, innovative development of the economy, do not thrive in a climate of artificial cutting back of knowledge, but only in one of openness and liberality." (FA-CI 2002; translated)

Obtaining this "climate" also poses great challenges! But why should that which applies to the knowledge culture of sustainability, the shaping of the electronic area, and the building up of a "knowledge-based society" be different from that which applies to the culture of humankind over all? It needs to prove itself to the external and the internal nature in view of the tasks that it puts to itself. Culture is therefore less a passive taking in and much more an active creation. In this sense I will finish with a "bon mot" from Antoine de Saint-Exupéry, a wellknown pilot and story-teller, who says that:

"A culture is based on that which is demanded from the people and not on that which they are given." 


\section{Literature}

Baker, S. (2000): The European Union: Integration, Competition, Growth - and Sustainability. In: Lafferty, W. M.; Meadowcroft, J. (eds.): Implementing Sustainable Development - Strategies and Initiatives in High Consumption Societies. Oxford, pp. 303-336

Bangemann, M. et al. (1994): Europa und die globale Informationsgesellschaft. Empfehlungen für den Europäischen Rat. Brüssel (CD-84-94-290-C)

Banse, G.; Metzner-Szigeth, A. (2003): Veränderungen im Quadrat: Computervermittelte Kommunikation und moderne Gesellschaft. Überlegungen zum Design des europäischen Forschungs-Netzwerks „Kulturelle Diversität und neue Medien“. In: Theory of science. Journal for theory of science, technology \& communication, Vol. XI (XXIV)/ No. 1, pp. 7-44

Bühl, A. (2000): Die Virtuelle Gesellschaft des 21. Jahrhunderts. Sozialer Wandel im Digitalen Zeitalter. Opladen

Castells, M. (1996): The Information Age: Economy, Society and Culture. Vol. I: The Rise of the Network Society. Malden, Oxford

EC - European Commission (1994): Europe's Way to the Information Society - An Action Plan. Communication from the Commission to the Council and the European Parliament and to the Economic and Social Committee and the Committee of Regions. Luxemburg (COM [1994] 347)

EC - European Commission (1997): Building an Information Society for us all. Final policy report of the high-level expert group. Maastricht (http://europa.eu.int/comm/employment_social/soc-dial/info_soc/esdis/buildingen.pdf)

EC - European Commission (2002): Sixth Framework Programme, Priority 7, Citizens and governance in a knowledge based society, Work Programme 2002-2003 (http://www. cordis.lu/citizens/home.html [12.12.2002])

EC-FIS - European Commission, Forum Information Society (2000): A European way for the information society. Luxembourg (Office for Official Publications of the EC)

EC-IST - European Commission, Information-Society-Technology-Programme: A European Way for the Information Society (http://www.cordis.lu/ist/ [25.09.2003])

European Council (2000): Presidency Conclusions, Lisbon Summit, March 23-24, 2000 (http://www.europarl.eu.int/summits/lis1_en.htm [03.03.2004])

FA-CI - Fachausschuß Information und Kommunikation der Deutschen UNESCO-Kommission (2002): Gemeinsame Fachausschußsitzung der Deutschen UNESCO-Kommission zum Thema „Nachhaltige Entwicklung“. Vorschlag Fachausschuß Information und Kommunikation (FA-CI), zur Verabschiedung auf der Hauptversammlung der Deutschen UNESCO-Kommission 2002 in Nürnberg, Entwurf. Nürnberg (http://www.infwiss.uni-konstanz.de/People/RK/Publikationen2002/nachhaltigkeit-fa-ci-entwurf0902. pdf [25.09.2003])

Hilty, L. M.; Ruddy, T. (2002): Resource Productivity in the Information Age. In: Futura, Vol. 21/No. 2, pp. 76-84 (http://www.internetix.fi/futuralehti/2002_2/02_2_076-084.pdf)

Hodgson, G. M. (2000): Socio-economic Consequences of the Advance of Complexity and Knowledge. In: OECD (ed.): The Creative Society of the $21^{\text {st }}$ Century. Paris, pp. 89112 
Johnston, P. (Ed.) (2002): Visions and Roadmaps for Sustainable Development in a Networked Knowledge Society. Report of a Workshop Co-chaired by the Presidents of the Brussels EU-Chapter of the Club of Rome and the "Factor 10 Institute". Brussels (European Commission, DG - Information Society Technologies)

Jokinen, P.; Malaska, P.; Kaivo-oja, J. (1998): The Environment in an "Information Society". A Transition Stage Towards More Sustainable Development? In: Futures, Vol. 30/No. 6, pp. 485-498

Kates, R. W.; Clark, W. C.; Corell, R.; Hall, J. M.; Jaeger, C. C.; Lowe, I.; McCarthy, J. J.; Schellnhuber, H. J.; Bolin, B.; Dickson, N. M.; Faucheux, S.; Gallopin, G. C.; Grubler, A.; Huntley, B.; Jäger, J; Jodha, N. S.; Kasperson, R. E.; Mabogunje, A.; Matson, P.; Mooney, H.; Moore III, B.; O'Riordan, T.; Svedlin, U. (2001): Sustainability Science. In: Science, Vol. 292, pp. 641-642

Keil-Slawik, R. (1996): Die Zukunft der Informationsgesellschaft, oder: Bangemannen gilt nicht. In: Tauss, J.; Kollbeck, J.; Mönikes, J. (Hg.): Deutschlands Weg in die Informationsgesellschaft. Herausforderungen und Perspektiven für Wirtschaft, Wissenschaft, Recht und Politik. Baden-Baden, pp. 855-863

Kopfmüller, J.; Brandl, V.; Jörissen, J.; Paetau, M.; Banse, G.; Coenen, R.; Grunwald, A. (2001): Nachhaltige Entwicklung integrativ betrachtet. Konstitutive Elemente, Regeln, Indikatoren. Berlin

Kuhlen, R. (2003): Bausteine zur Entwicklung einer Wissensökologie. Plädoyer für eine nachhaltige Sicht auf den UN-Weltgipfel zur Informationsgesellschaft (WSIS). Konstanz 2003 (http://www.inf-wiss.uni-konstanz.de/People/RK/Texte/bausteine-oekologie-wissen-endtext_rk-0203-v3.pdf [06.10.2003])

Lubbers, R.; Koorevaar, J. (2000): Primary Globalisation, Secondary Globalisation, and the Sustainable Development Paradigm. Opposing Forces in the $21^{\text {st }}$ Century. In: OECD (Ed.): The Creative Society of the $21^{\text {st }}$ Century. Paris, pp. 173-190

Metzner, A. (1998): Constructions of Environmental Issues in Scientific and Public Discourse. In: Müller, F.; Leupelt, M. (eds.): Eco Targets, Goal Functions and Orientors. Berlin a.o., pp. 171-192

Metzner, A. (2002): Die Tücken der Objekte. Über die Risiken der Gesellschaft und ihre Wirklichkeit. Frankfurt/M. a.o.

Schomberg, R. von (2002): The objective of Sustainable Development: Are we coming closer? Brussels (European Commission (DG for Research). Foresight Working Paper Series No. 1)

Spangenberg, J.; Mesicek, R.; Metzner, A.; Luks, F. (2002): Sustainability Indicators for the Knowledge-based Society. Measuring the Sustainability of the Information Society. In: Futura, Vol. 21/No. 2, pp. 85-95 (http://www.internetix.fi/futuralehti/2002_2/02_2_085095. pdf)

Stehr, N. (2001): Economy and Ecology in an Era of Knowledge-Based Economies. In: Current Sociology, Vol. 49/No. 1, pp. 67-90 